\title{
Optical Illusion
}

National Cancer Institute

\section{Source}

National Cancer Institute. Optical Illusion. NCI Thesaurus. Code C34865.

The visual perception of an image that differs from the reality of the image. 